\title{
SYNTHESIS OF LITHIUM AND COBALT OXIDES SYSTEMS BY THE ALD METHOD TO OBTAIN LITHIUM COBALT OXIDE CATHODE FOR THIN-FILM LIBS
}

\author{
Ilya MITROFANOV, Ilya EZHOV, Yury KOSHTYAL, Denis NAZAROV, Artem KIM, \\ Aleksander RUMYANTSEV, Anatoly POPOVICH, Maxim MAXIMOV \\ ${ }^{1}$ Peter the Great Saint-Petersburg Polytechnic University, Saint-Petersburg, Russian Federation, \\ maximspbstu@mail.ru
}

https://doi.org/10.37904/nanocon.2019.8672

\begin{abstract}
The development of micro- and nanoscale power sources for micro size electronic devices such as wireless sensors, biomedical implants, and smart cards is an important task. In this work, the processes of synthesis uniform lithium oxide, cobalt oxide, and lithium cobalt oxide thin films using atomic layer deposition (ALD) method were studied. Lithium tert-butoxide $(\mathrm{LiOtBu})$ and cobaltocene $\left(\mathrm{Co}(\mathrm{Cp})_{2}\right)$ were used as precursors. Remote oxygen plasma was used as a counter-reagent. The synthesis was carried out at $300{ }^{\circ} \mathrm{C}$. The growth rate and uniformity of the films were controlled by adjustment the precursor's evaporation temperature, reagent pulse time, and purge times. Monocrystalline silicon and stainless steel (SS316) were used as substrates. The films were studied by spectral ellipsometry, energy-dispersive X-ray spectroscopy (EDX) and X-ray diffraction analysis (XRD). Results showed that an increase the purge time to $10 \mathrm{~s}$ after the reagent pulse positively affects the uniformity of the films. The growth rates of $\mathrm{Li}-\mathrm{O}$ and Co-O systems were $0.080 \pm 0.010 \mathrm{~nm} /$ cycle and $0.022 \pm 0.003 \mathrm{~nm} /$ cycle, respectively. XRD data showed the presence of the crystalline CoO phase for the Co$\mathrm{O}$ and the presence of the $\mathrm{LiCoO}_{2}$ for $\mathrm{Li}-\mathrm{Co}-\mathrm{O}$ samples. The optimized synthesis parameters determined for $\mathrm{Li}-\mathrm{O}$ and $\mathrm{Co}-\mathrm{O}$ were subsequently used to synthesize $\mathrm{Li}-\mathrm{Co}-\mathrm{O}\left(\mathrm{LiCoO}_{2-\mathrm{x}}\right)$ system. According to the growth rates of $\mathrm{Li}-\mathrm{O}$ and $\mathrm{Co}-\mathrm{O}$, the ratio of $\mathrm{Li}$ and $\mathrm{Co}$ pulses was set as $1 / 5$. XRD data showed well crystalline $\mathrm{LiCoO}_{2}$ textured in (003) direction for as-deposited Li-Co-O thin films. According to cyclic voltammetry (CV), there is a pronounced peak characterizing of the change in the oxidation state of cobalt from $3+$ to $4+$. Based on cyclic tests, the Li-Co-O films have high coulombic efficiency.
\end{abstract}

Keywords: Atomic layer deposition, lithium oxide, cobalt oxide, lithium cobalt oxide, lithium-ion batteries, solid-state lithium-ion batteries

\section{INTRODUCTION}

Today lithium-ion batteries (LIBs) are widespread for power supply in modern portable electronics, sensors, medical devices, etc. The downscale trend in portable electronics requires the on-board power supply device to be of smaller dimensions, higher energy, and power density. Therefore, the production of thin-film anode and cathode materials is one of the most important task for the development modern portable electronic devices. Atomic layer deposition (ALD) is the most promising technology for synthesis inorganic thin films due to the ability to control the composition and thickness of the films with high precision. ALD is based on selflimited chemical reactions of gas-phase reagent with substrate surface [1,2]. Some examples of synthesis electrode materials by ALD method and their electrochemical properties can be found somewhere [3-5]. However, most of the work on the use of ALD for preparation of active materials is devoted to the synthesis of thin film anodes. There is much less work to synthesize cathode materials. The problem is the cathode materials contain lithium, which is difficult to produce by ALD due to hydrolysis when using water as a counterreagent. However, the use of oxygen plasma as a counter-agent can solve this problem. $\mathrm{LiCoO}_{2}$ is the most commonly used cathode material in commercial LIBs due to its high energy density, low self-discharge and excellent cyclability. Therefore in this work we synthesized the lithium cobalt oxide thin films by ALD using oxygen plasma as counter-reagent and studied its electrochemical performance. 


\section{MATERIALS AND METHODS}

The deposition of Li-O, Co-O, Li-Co-O films was carried out by ALD with Picosun R-150 setup at $300{ }^{\circ} \mathrm{C}$ at base pressure of 8-12 hPa. Lithium tert-butoxide (LiOtBu, 97\%, Sigma Aldrich) and bis(cyclopentadienyl) Cobalt(II) ( $\mathrm{Co}(\mathrm{Cp})_{2}, 99 \%$ Sigma-Aldrich), were used as metal-containing reagents. Remote oxygen plasma $\left(\mathrm{O}_{2}-\mathrm{p}\right)$ applied as a counter-reagent The temperatures of reagent containers were $218^{\circ} \mathrm{C}$ for LiOtBu, and 100 $175{ }^{\circ} \mathrm{C}$ for $\mathrm{Co}(\mathrm{Cp})_{2}$. All depositions were performed as follows. After pulsing of metal-containing reagent (LiOtBu - 1.0s or $\left.\mathrm{Co}(\mathrm{Cp})_{2}-1.6-3.0 \mathrm{~s}\right)$ the excess of the precursor was purged with nitrogen $(99.999 \%)$ before the counter-reagent was introduced. For increasing of vapor pressure of LiOtBu boosting ALD regime[6] was tested. Boosting parameters (Picohot ${ }^{\mathrm{TM}}$ Boosting), $500 \mathrm{sccm} / 0.5 \mathrm{~s} / 1.2 \mathrm{~s} / 0 \mathrm{~s}$ (boost/pre empty/master fill/postempty) was used. Pulse times for $\mathrm{O}_{2}$ plasma was $10 \mathrm{~s}$. To prevent Li-O thin films hydrolysis, 50 ALD cycles of trimethylaluminum (TMA)- $\mathrm{H}_{2} \mathrm{O}$ were applied for deposition of alumina protective coatings [7]. For deposition of $\mathrm{Li}-\mathrm{Co}-\mathrm{O}$ thin films we used super cycles consisting of one $\mathrm{LiOtBu} / \mathrm{O}_{2}-\mathrm{p}$ pulses and five $\mathrm{Co}(\mathrm{Cp})_{2} / \mathrm{O}_{2}-\mathrm{p}$ pulses: $\left[\mathrm{LiOtBu} / \mathrm{O}_{2}-\mathrm{p}\right]+\left[\mathrm{Co}(\mathrm{Cp})_{2} / \mathrm{O}_{2}-\mathrm{p}\right]^{*} 5$. We used 100 and 400 supercycles. Monocrystalline silicon wafers (surface orientation 100, the size $4 \times 4 \mathrm{~cm}$, Telecom-STV Co., LTD, Zelenograd, Moscow, Russia) and stainless-steel plates (316SS, Tob New Energy Technology Co., LTD, diameter $15.8 \mathrm{~mm}$ ) were used as substrates. Before deposition, silicon substrates were cleaned in an ultrasonic bath in acetone and deionized water for 15 min.

The thicknesses of the films were measured by spectral ellipsometry (vawelength range 350-1000 nm) using Ellips-1891 SAG ellipsometer (CNT, Novosibirsk, Russia). X-ray diffraction (XRD) studies were performed using a Bruker D8 ADVANCE (Cu-Ka). The obtained results were processed by the Rietveld method using TOPAS 5 software (XRD). The morphology and chemical composition of the films was studied by energydispersive X-ray spectroscopy (EDX) using Mira-3M (Tescan, Quanta 200, FEI).

Electrochemical studies were performed in CR2032 coin cells. The samples of Li-Co-O deposited on the 316SS surface were used. Lithium foil, polyolefin porous film 2325 (Celgard, Charlotte, NC, USA), and TCE918 (Tinci, Guangzhou, China) solution were used as the counter electrode, separator, and electrolyte, respectively. Coin cells were assembled in an argon glove box OMNI-LAB (VAC). Cyclic voltammetry (CV) was performed using a potentiostat PGSTAT302N+ (Autolab, Utrecht, the Netherlands) in the range of 3.0 $4.3 \mathrm{~V}$ with a scan rate of $0.5 \mathrm{mV} / \mathrm{s}$. Cyclic charge/discharge was performed using the battery testing system CT-3008W-5V10mA (Neware, Shenzhen, China) at room temperature in the range of potential $3.0-4.3 \mathrm{~V}$, at current $20-80 \mu \mathrm{A}$.

\section{RESULTS AND DESCUSSION}

\subsection{Li-O system}

Lithium butoxide is the most commonly used reagent for the synthesis of lithium-containing thin films by ALD [8]. The temperature of evoparation of lithium butoxide varies over a wide range from 90 to $180^{\circ} \mathrm{C}[4,9]$. Such a large temperature difference depends on the design features of the setups $[4,9]$. Our results showed that the $\mathrm{Li}-\mathrm{O}$ growth of the films occurs only at the maximum possible temperature of the evaporator $\left(218{ }^{\circ} \mathrm{C}\right)$ on the installation used (Picosun R-150) with a pulse duration of 3 seconds. In this regard, experiments were carried out to study the uniformity of coatings at various purge times and two precursor pulse modes: line boost mode (Picohot ${ }^{\mathrm{TM}}$ Boosting) and under standard mode. Picohot ${ }^{\mathrm{TM}}$ Boosting is provided by the manufacturer for the low volatile reagent to reduce the temperature of the evaporator. In this work, the lithium reagent pulse time is $1.6 \mathrm{~s}$ (Boosting) and 3.0 (Standard mode). The temperature of the evaporator at Standard and Boosting modes was $218^{\circ} \mathrm{C}$.

It should be noted that the reagent is low volatile and stable up to $250{ }^{\circ} \mathrm{C}$ [10], which imposes restrictions on the minimum temperature for the synthesis of lithium-containing films. Based on the literature data and taking into account the physicochemical characteristics of the reagents, the reactor temperature was set at $300{ }^{\circ} \mathrm{C}$. 
All films, in accordance with our previous studies [7] on the preparation of lithium-containing films, were coated with a protective layer of alumina ( 50 ALD cycles $-\mathrm{TMA}+\mathrm{H}_{2} \mathrm{O}$ ) and stored in an inert atmosphere of argon.

The effect of purge time on the growth rate and uniformity of the films using two types of reagent pulse modes (Standard and Boosting) shown in Figure 1. With increasing purge time, uniformity of coatings increases and the growth rate decreases for both modes. Acceptable growth rate and uniformity of the films was obtained by pulse $10-15 \mathrm{~s}$. To optimize the synthesis time, a purge of $10 \mathrm{~s}$ was chosen for subsequent experiments. It is worth noting that when using Boosting, the growth rate more than 2 times lower than with Standard pulse mode. To increase the growth rate of the films, the conditions with the highest growth rates with similar uniformity were chosen for Li-Co-O deposition. XRD data didn't show presence of any crystalline phase.

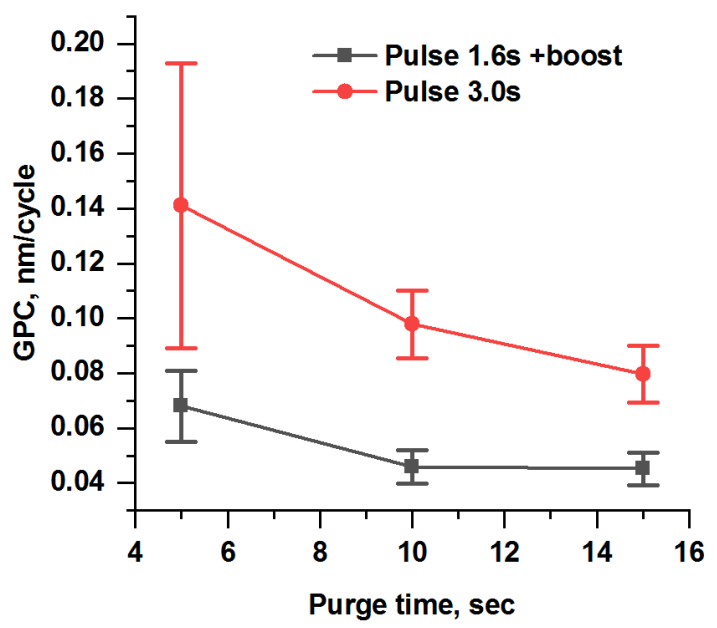

Figure 1 The change of growth per cycle (GPC) with an increase in the purge time of LiOtBu

\subsection{Co-O system}

The literature provides information on the synthesis of $\mathrm{CoO}_{x}$ films by the ALD in a wide temperature range using cobaltocene and ozone or oxygen plasma as a counter-reagent. The synthesis is carried out in a wide temperature range $\left(140-350{ }^{\circ} \mathrm{C}\right)[11,12]$. However, to synthesize the lithium cobaltate, it is necessary to combine the deposition temperature of cobalt and lithium oxides (for $\mathrm{Li}-\mathrm{O}$ the temperature is at least $300{ }^{\circ} \mathrm{C}$ ). Therefore to optimize the deposition conditions of cobalt oxide, we used a temperature of $300{ }^{\circ} \mathrm{C}$.

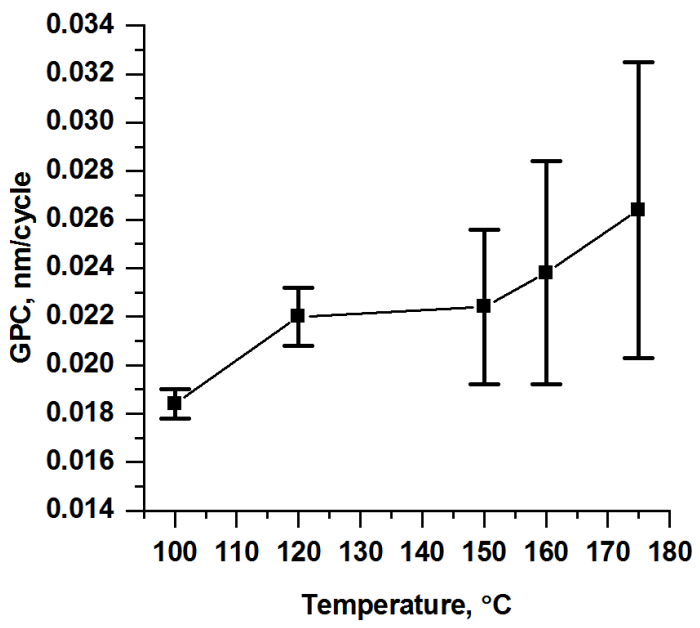

Figure 2 The change of growth per cycle (GPC) with an increase in the evaporation temperature of $\mathrm{Co}(\mathrm{Cp})_{2}$ 
Based on our previous work [13], when the nickelocene $\left(\mathrm{NiCp}_{2}\right)$ was used as ALD precursor for NiOx thin film synthesis we used 1.0 second for pulse and 10 second for purge. As we found out earlier, the temperature of the source is of great importance when using metallocenes. In this regard, we studied the effect of evaporator temperature on growth rate and uniformity $\mathrm{Co}-\mathrm{O}$ films (Figure 2). The optimal temperature range was from 120 to $150{ }^{\circ} \mathrm{C}$. At higher temperatures, the growth rate increases, but the gradient of film thickness also increases significantly, which may be caused by the decomposition of cobaltocene.

EDX data showed the presence of cobalt in the film. Figure 3 shows the diffraction pattern of Co-O sample deposited on silicon surface. Three peaks at 33, 55 and 57 degree are associated with the imperfection of the crystal structure of the silicon substrate. The other peaks correspond to the CoO phase $(\mathrm{Fm}-3 \mathrm{~m})$. The coincidence of the intensities of these peaks with the table value indicates the absence of texture in the film.

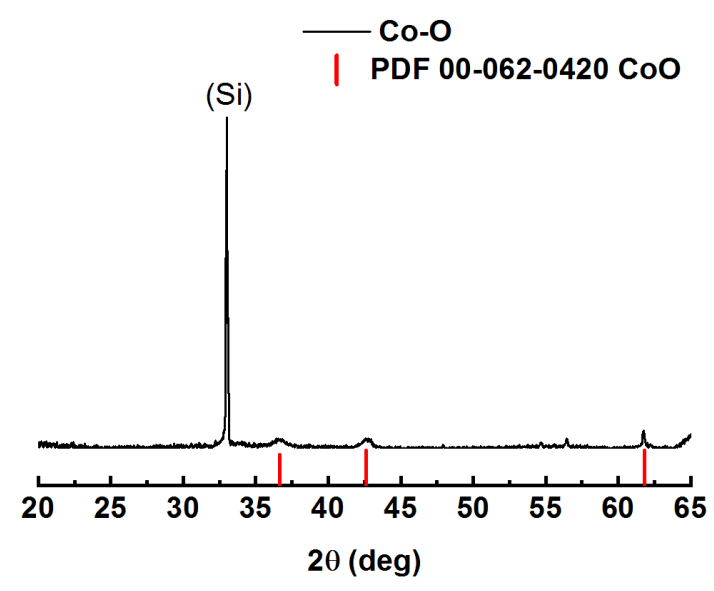

Figure 3 XRD of Co-O thin film

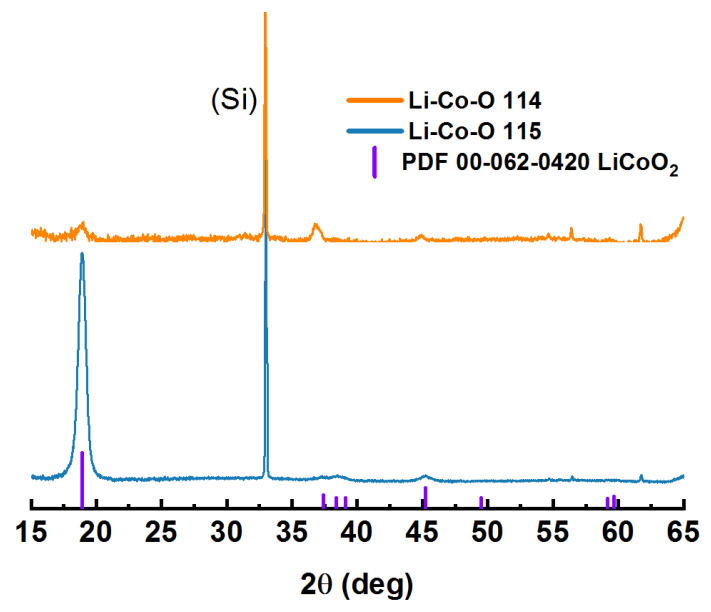

Figure $4 \mathrm{XRD}$ of Li-Co-O thin films

\subsection{Li-Co-O system synthesis and electrochemical perfomance}

Based on the results of experiments with $\mathrm{Li}-\mathrm{O}$ and $\mathrm{Co}-\mathrm{O}$, the optimal parameters were used for the synthesis of Li-Co-O films. We synthesize 2 samples using 100 and 400 super cycles. Each supercycle consisted of one $\mathrm{LiOtBu} / \mathrm{O}_{2}-\mathrm{p}$ pulses and five $\mathrm{Co}(\mathrm{Cp})_{2} / \mathrm{O}_{2}-\mathrm{p}$ pulses: $\left[\mathrm{LiOtBu} / \mathrm{O}_{2}-\mathrm{p}\right]+\left[\mathrm{Co}(\mathrm{Cp})_{2} / \mathrm{O}_{2}-\mathrm{p}\right]^{*} 5$. The thickness of the films were $34.2 \pm 4.2$ and $70.6 \pm 11.6 \mathrm{~nm}$ respectively.

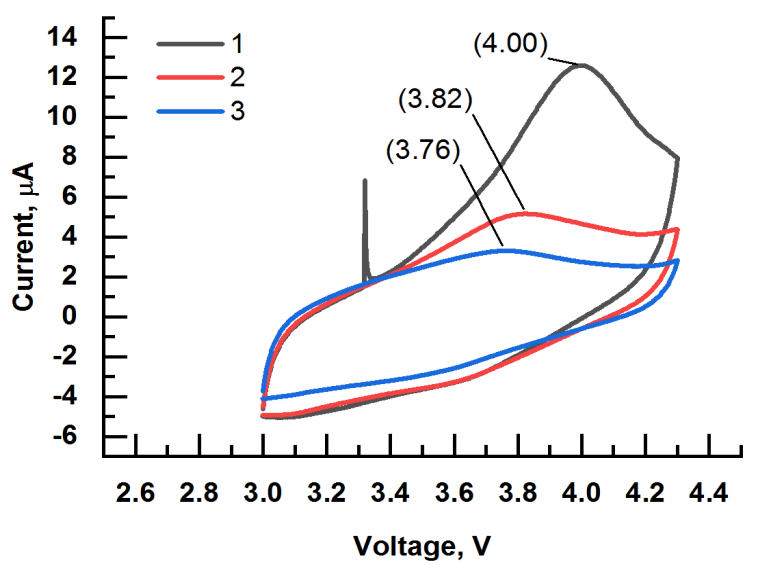

Figure $5 \mathrm{CV}$ of $\mathrm{Li}-\mathrm{Co}-\mathrm{O} 115$ thin film

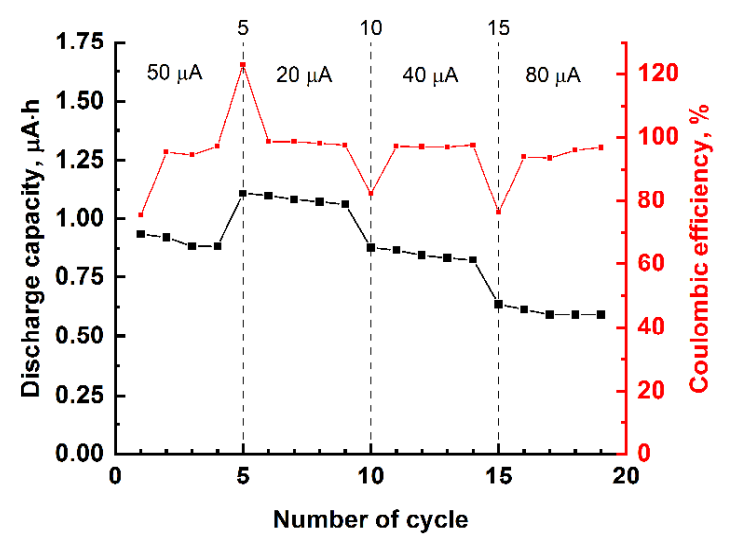

Figure 6 Effect of discharge current on capacity of Li-Co-O 115 film 
Presence of cobalt in the films were confirmed by EDX data. At the diffraction patterns of the samples (Figure 4) clearly visibly peaks of the silicon substrate (33, 55, 57 degree). But the other peaks are characteristic by the $\mathrm{LiCoO}_{2}$ structure with the space group $(\mathrm{R} \overline{3} \mathrm{~m})$. The X-ray diffraction pattern of sample with a larger film thickness shows a strong texturing of the $\mathrm{LiCoO}_{2}$ phase into the (003) direction which is perpendicular to the substrate surface. The March-Dallas coefficient was $0.3752 \pm 0.0064$. The unit cell parameters calculated by the Rietvelt method for samples thin and thick films were: $a=2.856 \pm 0.009$, $c=14.046 \pm 0.016$ and $a=2.815 \pm 0.002, c=14.065 \pm 0.002$ respectively. which fits well with tabular values [14]. The difference in the lattice parameter "a" for a thin film may be due to surface effects.

The resulting samples were investigated by cyclic voltammetry (Figure 5 ). An intense peak in region $4 \mathrm{~V}$ is characteristic of the process of cobalt oxidation from $3+$ to $4+$. [15,16], while there is no pronounced peak for the reverse process (reduction processes from $4+$ to $3+$ ). Also, there is a decrease in the anode peak and its displacement in the region of lower potentials. All of the above can be associated with the involvement of the substrate material in the process [13]. The areas of the anodic and cathodic curves on cycles 2 and 3 are comparable, which may indicate good reversibility of the process. Figure $\mathbf{5 b}$ shows the dependence of the discharge capacitance on the number of cycles at various currents. A stepwise increase in the discharge current from 20 to $80 \mu \mathrm{A}$ leads to a marked decrease in the discharge capacitance, which is similar for all electrode materials. Coulombic efficiency is about $95 \%$. (Figure 6) The average discharge capacity was $0.85 \mu \mathrm{Ah}$. The average specific discharge capacity is $37 \mathrm{mAh} / \mathrm{g}$, which is less than the values obtained in practice for powder analogues (practical capacity of $\mathrm{LiCoO}_{2}$ is only $\sim 137 \mathrm{mAh} / \mathrm{g}$, while the theoretical capacity of $\sim 274 \mathrm{mAh} / \mathrm{g}$ [15]), this may be due to the involvement of the substrate material in the process.

\section{CONCLUSION}

ALD-growth of Li-O, Co-O, and Li-Co-O films was carried out using lithium butoxide, cabaltocene, and remote oxygen plasma. The growth rates of $\mathrm{Li}-\mathrm{O}$ and $\mathrm{Co}-\mathrm{O}$ systems were $0.080 \pm 0.010 \mathrm{~nm} /$ cycle and $0.022 \pm 0.003$ $\mathrm{nm} /$ cycle, respectively. Results showed that an increase the purge time to $10 \mathrm{~s}$ positively affects the uniformity of the films. The presence of cobalt in the films was confirmed by the EDX method. In contrast to the results presented in literature $[3,11]$ the synthesized $\mathrm{Co}-\mathrm{O}$ and $\mathrm{Li}-\mathrm{Co}-\mathrm{O}$ films contain well crystalline $\mathrm{CoO}$ and $\mathrm{LiCoO}_{2}$ phases respectively. For as-deposited $\mathrm{Li}-\mathrm{Co}-\mathrm{O}$ thin films, $\mathrm{LiCoO}_{2}$ phase textured in (003) direction. According to $\mathrm{CV}$ study, there is a pronounced peak characterizing of the change in the oxidation state of cobalt from 3+ to $4+$. Based on cyclic tests, the Li-Co-O films have high coulombic efficiency.

\section{ACKNOWLEDGEMENTS}

\section{The research was conducted under the financial support from the grant of the President of the} Russian Federation, Grant No. MK-2961.2018.3.

\section{REFERENCES}

[1] MALYGIN, A.A.; DROZD, V.E.; MALKOV, A.A.; SMIRNOV, V.M. From V. B. Aleskovskii's "Framework" Hypothesis to the Method of Molecular Layering/Atomic Layer Deposition. Chem. Vap. Depos. 2015, 21, 216240.

[2] PUURUNEN, R.L. Surface chemistry of atomic layer deposition: A case study for the trimethylaluminum/water process. J. Appl. Phys. 2005, 97.

[3] NILSEN, O.; MIIKKULAINEN, V.; GANDRUD, K.B.; ØSTRENG, E.; RUUD, A.; FJELLVÅG, H. Atomic layer deposition of functional films for Li-ion microbatteries. Phys. status solidi 2014, 211, 357-367.

[4] WANG, B.; LIU, J.; SUN, Q.; LI, R.; SHAM, T.-K.; SUN, X. Atomic layer deposition of lithium phosphates as solidstate electrolytes for all-solid-state microbatteries. Nanotechnology 2014, 25, 504007. 
[5] MAXIMOV, M.Y.; KOSHTYAL, Y.; MITROFANOV, I.; EZHOV, I.; RUMYANTSEV, A.; POPOVICH, A. Features of the synthesis of lithium-based ternary oxide nanofilms by atomic layer deposition with LHMDS for thin-film LIBs. In Proceedings of the Materials Today: Proceedings; INESS-2019, 2019.

[6] PFEIFFER, K.; SCHULZ, U.; TÜNNERMANN, A.; SZEGHALMI, A. Ta 2 O 5 / Al 2 O 3 / SiO 2 - antireflective coating for non-planar optical surfaces by atomic layer deposition.; von Freymann, G., Schoenfeld, W. V., Rumpf, R.C., Eds.; 2017; p. 1011513.

[7] NAZAROV, D.; EZHOV, I.; MITROFANOV, I.; MAXIMOV, M. The use of the TMA as stabilizing reagent for the Li-O system obtained by atomic layer deposition. Key Eng. Mater. 2019, 822, 787-794.

[8] NILSEN, O.; MIIKKULAINEN, V.; GANDRUD, K.B.; ØSTRENG, E.; RUUD, A. Atomic layer deposition of functional films for Li-ion microbatteries. In Proceedings of the Physica Status Solidi (A) Applications and Materials Science; 2014; Vol. 211, pp. 357-367.

[9] HÄMÄLÄINEN, J.; HOLOPAINEN, J.; MUNNIK, F.; HATANPÄÄ, T.; HEIKKILÄ, M.; RITALA, M.; LESKELÄ, M. Lithium Phosphate Thin Films Grown by Atomic Layer Deposition. J. Electrochem. Soc. 2012, 159, A259-A263.

[10] CHISHOLM, M.H.; DRAKE, S.R.; NAIINI, A.A.; STREIB, W.E. The synthesis and characterization of volatile lithium alkoxides, and the single crystal X-ray structure of [LiOCMe2Ph]6. Polyhedron 1991, 10, 805-810.

[11] DONDERS, M.E.; ARNOLDBIK, W.M.; KNOOPS, H.C.M.; KESSELS, W.M.M.; NOTTEN, P.H.L. Atomic layer deposition of LiCoO2 thin-film electrodes for all-solid-state Li-ion micro-batteries. J. Electrochem. Soc. $2013,160$.

[12] DISKUS, M.; NILSEN, O.; FJELLVÅG, H. Thin Films of Cobalt Oxide Deposited on High Aspect Ratio Supports by Atomic Layer Deposition. Chem. Vap. Depos. 2011, 17, 135-140.

[13] KOSHTYAL, Y.; NAZAROV, D.; EZHOV, I.; MITROFANOV, I.; KIM, A.; RYMYANTSEV, A.; LYUTAKOV, O.; POPOVICH, A.; MAXIMOV, M. Atomic Layer Deposition of NiO to Produce Active Material for Thin-Film LithiumIon Batteries. Coatings 2019, 9, 301.

[14] SITA, L.E.; DA SILVA, S.P.; DA SILVA, P.R.C.; SCARMINIO, J. Re-synthesis of LiCoO2extracted from spent Liion batteries with low and high state of health. Mater. Chem. Phys. 2017, 194, 97-104.

[15] NIE, P.; SHEN, L.; LUO, H.; LI, H.; XU, G.; ZHANG, X. Synthesis of nanostructured materials by using metalcyanide coordination polymers and their lithium storage properties. Nanoscale 2013, 5, 11087.

[16] JULIEN; MAUGER; HUSSAIN Sputtered LiCoO2 Cathode Materials for All-solid-state Thin-film Lithium Microbatteries. Materials (Basel). 2019, 12, 2687. 